\title{
Monitoring Tekanan Gas Medis pada Instalasi Gas Medis Rumah Sakit
}

\author{
Nur Hudha Wijaya*1 ${ }^{*}$, Bambang Untara ${ }^{2}$, Intivada Khoirunnisa ${ }^{3}$ \\ Universitas Muhammadiyah Yogyakarta, Indonesia
}

\section{INFO ARTIKEL}

\author{
Alamat Web Artikel: \\ Journal.umy.ac.id/index.php/
}

$\mathrm{mt} /$ article/view/5930

DOI:

https://doi.org/10.18196/mt.010104

Data Artikel:

Diterima:

19 Okt 2019

Direview:

21 Okt 2019

Direvisi:

24 Okt 2019

Disetujui:

31 Okt 2019

Korespondensi:

nurhudhawijaya@umy.ac.id

\begin{abstract}
ABSTRAK
Faktor pendukung dalam kesehatan pasien di Rumah Sakit diantaranya gas medis, gas harus bersih dan memiliki kemurnian tinggi dan tekanan yang stabil. Selama ini Rumah Sakit masih menggunakan regulator gas medis konvensional, dimana kran regulator tersebut pada saat dibuka, akan langsung menunjukkan ukuran tekanan gas yang ada dalam isi tabung tersebut namun belum terkandung informasi low and high pressure sehingga perawat masih menggunakan ilmu prakiraan untuk menentukan bahwa gas tersebut sudah habis atau melemahnya tekanan gas. Dengan kondisi tersebut, maka dirancang sebuah alat monitoring tekanan instalasi gas medis digital yang berfungsi melakukan pemantauan gas medis yang dapat menunjukkan informasi indikator low and high pressure yang tertampil pada layar $L C D$ dengan penanda suara buzzer. Alat ini bekerja dengan cara memantau tekanan pada tabung gas medis yang memanfaatkan sensor tekanan MPX5700 yang dikendalikan oleh sistem mikrokontroler ATMega 8. Dengan alat monitoring tekanan gas medis digital ini dilakukan pengujian dengan tekanan $300 \mathrm{kPa}$ dan didapatkan rata-rata 286,6 dengan simpangan 13,4 dan error 4,46 $\%$, dengan tekanan $400 \mathrm{kPa}$ didapatkan rata-rata 396,75 dengan simpangan 3,25 dan error $0,81 \%$, dengan tekanan $500 \mathrm{kPa}$ didapatkan rata-rata 491,95 dengan simpangan 8,05 dan error $1,61 \%$, dengan tekanan $550 \mathrm{kPa}$ didapatkan rata-rata 539,75 dengan simpangan 10,25 dan error 1,86\%. Berdasarkan hasil pengujian tersebut, alat tekanan gas medis dapat digunakan untuk tekanan 0 sampai $550 \mathrm{kPa}$, artinya alat dapat bekerja dengan baik.
\end{abstract}

Kata Kunci: Monitoring, MPX5700, ATMega8, Gas Medis

\section{PENDAHULUAN}

Instalasi Gas Medis Menurut Kepmenkes No. 1439 / MENKES / SK / XI / 2002 tentang Penggunaan Gas Medis Pada Sarana Pelayanan Kesehatan, pemantauan dan analisis gas adalah bagian penting pada banyak bidang [1]. Gas Medik adalah gas dengan spesifikasi khusus yang dipergunakan untuk pelayanan medis pada fasilitas pelayanan kesehatan. Penggunaan Gas Medik dan Vakum Medik pada fasilitas pelayanan kesehatan di ruang operasi, ruang intensif, dan ruang gawat darurat harus dilakukan melalui penyaluran pada Sistem Instalasi Gas Medik dan Vakum Medik. Instalasi Gas Medis selanjutnya disingkat (IGM) adalah seperangkat sentral gas medis, instalasi pipa gas medis sampai kamar rawat inap/bangsal (outlet) [2]. Sistem sederhana saat pengiriman gas harus terkontrol dengan baik [3]. Jenis instalasi gas medis yang biasa dipasang untuk keperluan rumah sakit diantaranya ada Oxygen (O2), Nitrous Oxide (N2O), Medical Compressed Air (Breathing Air), dan Vacum (Suction), terdapat 2 bagian instalasi gas medis ada di sentral gas dan di bagian ruangan tertentu yang telah ditentukan seperti NICU, ICCU, PICU. Salah satu syarat instalasi gas medis adalah adanya suatu sistem untuk monitoring tekanan instalasi gas medis, dan itu memerlukan monitoring/alarm penanda khusus saat terjadinya masalah dalam instalasi gas medis. Ada 2 jenis sistem alarm pada gas medis yaitu master alarm (sentral) dan local area alarm, master alarm digunakan untuk monitoring semua masalah di sentral gas medis kemudian local area alarm untuk memonitoring semua masalah di area tertentu yang sudah ditetapkan sebelumnya [4]. Rancangan pengendali valve untuk mengatur membuka dan menutup set point [5] tentunya harus sudah terkalibrasi secara rutin karena memungkinkan dapat berubah sewaktu-waktu. 


\section{Wijaya, Untara, Khoirunnisa}

Monitoring Tekanan Gas Medis

Pada umumnya Rumah Sakit masih menggunakan regulator gas medis sebagai penanda isi gas dalam tabung tersebut bahwa gas tersebut masih ada, sehingga tidak diketahui secara akurat mengenai informasi low and high pressure pada gas medis, informasi tersebut adalah syarat tekanan kestabilan pada gas medis, jika terjadi penurunan atau kenaikan tekanan gas tanpa diketahui maka dapat membahayakan pasien.

Sebelumnya telah dilakukan Penelitian tentang karakteristik detektor oksigen berupa pelet dengan bahan utama $\mathrm{TiO} 2$ didoping oleh $\mathrm{CuO}$ [6]. Akuisisi data eksperimen telah dilakukan menggunakan oksida timah karena dianggap sangat sensitif [7].

Permasalahan di lapangan adalah pemakaian regulator yang belum dapat memfasilitasi dengan kelengkapan teknologi, sehingga menyebabkan tertundanya informasi pengiriman sinyal kepada tenaga medis yang seharusnya tertangani dengan cepat. Dengan kondisi tersebut akan mengakibatkan terganggunya kinerja dalam setiap instalasi gas medis di Rumah Sakit.

Oleh karena itu dilihat dari permasalahahan tersebut, maka diperlukan alat yang dapat memenuhi kebutuhan rumah sakit dalam hal ini alat monitoring tekanan gas medis. Dengan perkembangan teknologi yang sangat pesat penulis akan membuat suatu sistem monitoring tekanan instalasi gas medis dalam bentuk digital dan dilengkapi alarm indikator low and high presure, sistem ini juga akan sangat membantu user dalam permasalahan instalasi gas medis.

\section{METODE PENELITIAN}

Pada perancangan perangkat keras Alat Monitoring gas ini terdapat Power Supply, Minimum sistem dan sensor MPX5700. Sensor MPX5700 ini membaca tekanan dari 0-700kPa dan pada perancangan alat ini penulis menambahkan buzzer untuk indikator low and high pressure, buzzer low pressure akan berbunyi ketika tekanan di bawah $400 \mathrm{kPa}$ dan buzzer high akan berbunyi ketika tekanan diatas $500 \mathrm{kPa}$.

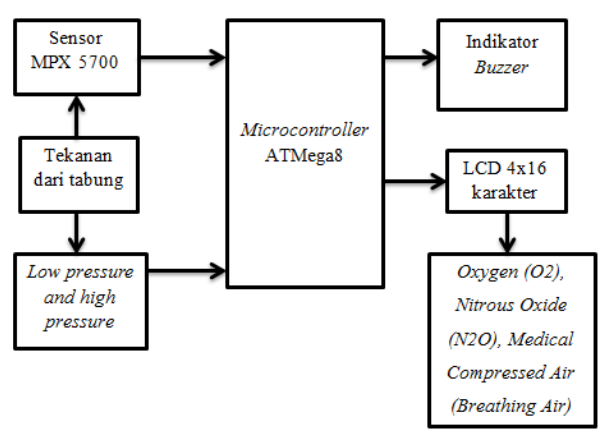

Gambar 1 Blok Diagram

Tekanan dari tabung akan dibaca oleh Sensor MPX 5700 yang akan mengubah nilai tekanan yang diberikan oleh instalasi gas medis menjadi satuan listrik. Output sensor ini langsung dimasukkan ke bagian ADC (analog to digital converter) mikrokontroler ATMega 8 dikarenakan output dari sensor sudah berkisar dari 0,2 VDC sampai 4,78 VDC sehingga tidak membutuhkan penguatan. Pembacaan nilai ADC yang merupakan pengubah sinyal analog ke sinyal digital inilah yang menjadi acuan untuk tampilan pada LCD, dan LCD akan menampilkan monitoring Oxygen $\left(\mathrm{O}_{2}\right)$, Nitrous Oxide $\left(\mathrm{N}_{2} \mathrm{O}\right)$, Medical Compressed Air (Breathing Air). Kemudian alarm berupa LED indikator serta buzzer juga menjadi acuan terjadinya low pressure and high presurre. Dalam minimum sistem pemrograman ATMega 8 menggunakan bahasa $\mathrm{C}$, program ini mengatur semua kinerja dari seluruh blok pada Gambar 1. 


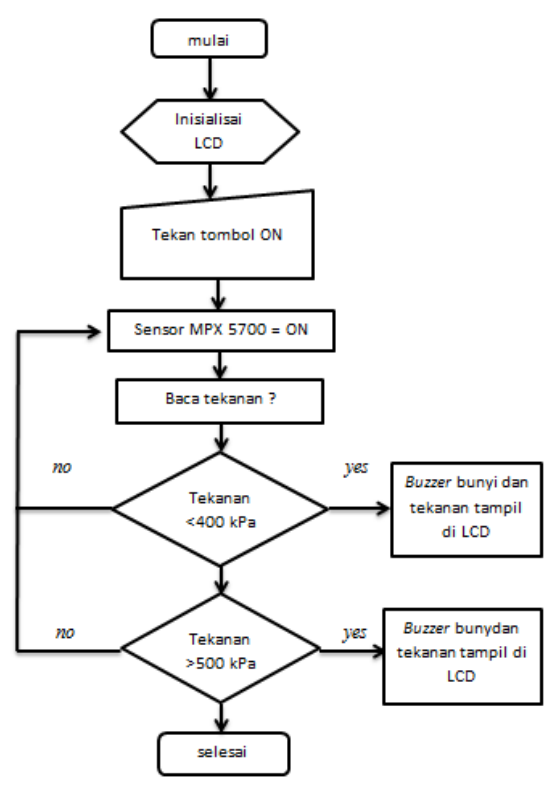

Gambar 2 Diagram Alir

Berdasarkan Gambar 2 dapat dijelaskan alur kerja alat sebagai berikut. Ketika alat dihidupkan, sistem melakukan inisialisasi dan pertama kali LCD akan menampilkan nama alat. Setelah selesai inisialisasi awal tekan tombol "ON" untuk menjalankan alat. Ketika tombol "ON" ditekan maka sensor MPX 5700 akan berkerja dan membaca tekanan. Minimum sistem akan membaca tekanan ketika tekanan kurang dari $400 \mathrm{kPa}$ maka buzzer akan berbunyi dan menunjukan data pada tampilan LCD. Ketika tekanan ketika tekanan diatas $400 \mathrm{kPa}$ maka sistem akan berjalan normal. Sistem kembali membaca tekanan ketika tekanan diatas $500 \mathrm{kPa}$ maka buzzer akan berbunyi dan menunjukkan data pada tampilan LCD. Ketika tekanan dibawah $500 \mathrm{kPa}$ maka sistem akan berjalan normal. Sistem akan melakukan proses yang sama seperti yang diatas mulai dari membaca tekanan ketika tekanan < $400 \mathrm{kPa}$ dan tekanan $>500 \mathrm{kPa}$ alarm akan berbunyi dan selebihnya sistem akan selalu memantau tekanan dan menampilkannya pada LCD.

\subsection{Karakteristik Sensor}

Sensor MPX 5700 merupakan sensor tekanan yang dapat mengukur tekanan maksimum 700 $\mathrm{kPa}$. Terdapat 3 macam tipe pengukuran yang bisa dilakukan oleh sensor ini yaitu type gauge, differentials, dan absolute.

Ada beberapa macam sensor MPX5700.

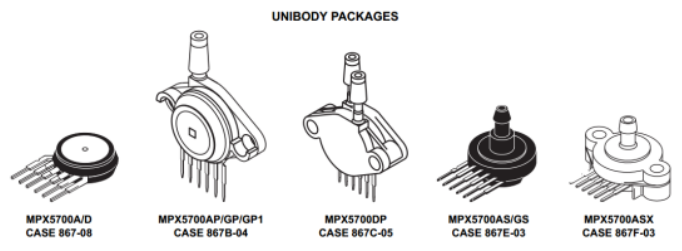

Gambar 3 Jenis - jenis sensor MPX 5700[8].

Sensor MPX5700 yang merupakan suatu sensor tekanan yang bekerja atau dapat mengukur hingga tekanan maksimum yaitu $700 \mathrm{kPa}$. Sensor ini bekerja dengan tegangan input 5 volt DC, dan tegangan output yang masih berupa tegangan analog sebesar 0,2 sampai 4,7 volt DC dengan tingkat sensitivas yaitu $6,4 \mathrm{mV} / \mathrm{kPa}$ [8]. Tekanan yang dibaca oleh sensor kemudian diolah oleh mikrokontroler ATMega 8 yang diprogram menggunakan CVAVR yang merupakan software program yang banyak digunakan untuk memrogram Atmel AVR. 


\section{Wijaya, Untara, Khoirunnisa}

Monitoring Tekanan Gas Medis

\subsection{Metode Pengujian dan Analisis}

Proses pengujian pembacaan tekanan gas oleh alat dilakukan di Laboratorium Teknik Elektromedik UMY. Pengujian pembacaan tekanan dilakukan pada beberapa titik tekanan diantaranya pada tekanan $300 \mathrm{kPa}, 400 \mathrm{kPa}, 500 \mathrm{kPa}$, dan $550 \mathrm{kPa}$.

Metode pengujian dilakukan dengan cara memberikan tekanan gas untuk alat pada tekanan $300 \mathrm{kPa}$, kemudian dilakukan pengukuran tegangan keluaran sensor menggunakan multitester. Hasil pembacaan multitester dibandingkan dengan datasheet sensor. Perbandingan tersebut digunakan sebagai data untuk mengetahui kebenaran pembacaan tekanan oleh alat. Demikian juga pada tekanan selanjutnya yaitu pada tekanan $400 \mathrm{kPa}, 500 \mathrm{kPa}$, dan $500 \mathrm{kPa}$ dilakukan proses pengukuran yang sama. Masing - masing titik tekanan dilakukan pengukuran sebanyak 20 kali.

Metode analisis pada penelitian adalah dengan menggunakan teknik analisis perhitungan ratarata, simpangan dan nilai error.

\section{HASIL DAN PEMBAHASAN}

Pengujian kinerja alat dilakukan di Lab. Elektromedik Universitas Muhammadiyah Yogyakarta. Karena kekurangan sumber daya maka pengujian dilakukan menggunakan kompresor dan data diambil berdasarkan tegangan kerja sensor yang didapatkan dari datasheet pabrik sensor yang digunakan. Tekanan yang digunakan dalam pengambilan data ini mulai dari $300 \mathrm{kPa}, 400 \mathrm{kPa}$, $500 \mathrm{kPa}$, dan $550 \mathrm{kPa}$.

\subsection{Hasil Pengukuran Tekanan pada $300 \mathrm{kPa}$}

Tabel 1 Perbandingan Tekanan Terhadap Tegangan Keluaran

\begin{tabular}{|c|c|c|c|}
\hline $\begin{array}{c}\text { Tekanan } \\
(\mathrm{kPa})\end{array}$ & Alat (VDC) & $\begin{array}{c}\text { Datasheet } \\
\text { (VDC) }\end{array}$ & Alarm \\
\hline 300 & 1.92 & 2.07 & on \\
\hline 300 & 1.93 & 2.07 & on \\
\hline 300 & 1.93 & 2.07 & on \\
\hline 300 & 1.94 & 2.07 & on \\
\hline 300 & 1.94 & 2.07 & on \\
\hline 300 & 1.94 & 2.07 & on \\
\hline 300 & 1.94 & 2.07 & on \\
\hline 300 & 1.94 & 2.07 & on \\
\hline 300 & 1.93 & 2.07 & on \\
\hline 300 & 1.94 & 2.07 & on \\
\hline 300 & 1.93 & 2.07 & on \\
\hline 300 & 1.94 & 2.07 & on \\
\hline 300 & 1.94 & 2.07 & on \\
\hline 300 & 1.94 & 2.07 & on \\
\hline 300 & 1.93 & 2.07 & on \\
\hline 300 & 1.94 & 2.07 & on \\
\hline 300 & 1.94 & 2.07 & on \\
\hline 300 & 1.94 & 2.07 & on \\
\hline 300 & 1.94 & 2.07 & on \\
\hline 300 & 1.94 & 2.07 & on \\
\hline \multicolumn{2}{|c|}{ Rata-rata } & 1.9365 & \\
\hline \multicolumn{2}{|c|}{ Simpangan } & 0.1335 & \\
\hline \multicolumn{2}{|c|}{ Error (\%) } & $6.44 \%$ & \\
\hline
\end{tabular}

Medika Teknika : Jurnal Teknik Elektromedik Indonesia, Vol 01 No. 1, Oktober $2019 \mid 22$ 


\section{Wijaya, Untara, Khoirunnisa}

Monitoring Tekanan Gas Medis

Berdasarkan Tabel 1, pada tekanan $300 \mathrm{kPa}$ didapatkan error sebesar 6,44\%. Nilai error tersebut masih berada dibawah ambang batas error yang diijinkan yakni $10 \%$. Pengambilan data pada titik ini dimaksudkan untuk menguji kerja alarm, dimana saat alat dilakukan setting batas indikator low dibawah $400 \mathrm{kPa}$ akan berbunyi alarm. Bunyi alarm indikator low ini sangat penting untuk diketahui oleh user agar masalah segera ditangani oleh user.

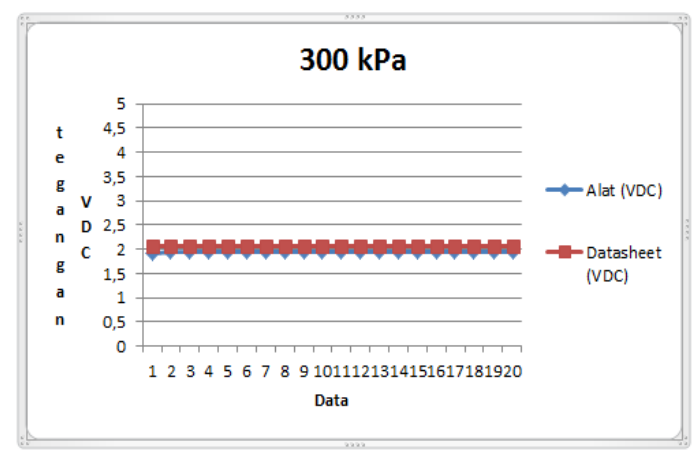

Gambar 4 Grafik Tegangan Alat Dan Datasheet

\subsection{Hasil Pengukuran Tegangan Pada Tekanan 500 kPa}

Tabel 2 Perbandingan Tekanan Terhadap Tegangan Keluaran

\begin{tabular}{|c|c|c|c|}
\hline $\begin{array}{c}\text { Tekanan } \\
(\mathrm{kPa})\end{array}$ & Alat (VDC) & $\begin{array}{c}\text { Datasheet } \\
\text { (VDC) }\end{array}$ & Alarm \\
\hline 500 & 3.32 & 3.4 & off \\
\hline 500 & 3.33 & 3.4 & off \\
\hline 500 & 3.34 & 3.4 & off \\
\hline 500 & 3.31 & 3.4 & off \\
\hline 500 & 3.32 & 3.4 & off \\
\hline 500 & 3.31 & 3.4 & off \\
\hline 500 & 3.31 & 3.4 & off \\
\hline 500 & 3.32 & 3.4 & off \\
\hline 500 & 3.32 & 3.4 & off \\
\hline 500 & 3.32 & 3.4 & off \\
\hline 500 & 3.32 & 3.4 & off \\
\hline 500 & 3.34 & 3.4 & off \\
\hline 500 & 3.31 & 3.4 & off \\
\hline 500 & 3.32 & 3.4 & off \\
\hline 500 & 3.31 & 3.4 & off \\
\hline 500 & 3.32 & 3.4 & off \\
\hline 500 & 3.31 & 3.4 & off \\
\hline 500 & 3.32 & 3.4 & off \\
\hline 500 & 3.32 & 3.4 & off \\
\hline 500 & 3.32 & 3.4 & off \\
\hline \multicolumn{2}{|c|}{ Rata-rata } & 3.3195 & \\
\hline \multicolumn{2}{|c|}{ Simpangan } & 0.0805 & \\
\hline \multicolumn{2}{|c|}{ Error $(\%)$} & $2.36 \%$ & \\
\hline
\end{tabular}




\section{Wijaya, Untara, Khoirunnisa}

Monitoring Tekanan Gas Medis

Berdasarkan Tabel 2, pada tekanan $500 \mathrm{kPa}$ didapatkan error sebesar 2,36 \%. Nilai error tersebut masih berada dibawah ambang batas error yang diijinkan yakni $10 \%$. Pengambilan data pada titik ini didasarkan untuk mengetahui apakah modul membaca tekanan dengan benar dan tidak memiliki error $>10 \%$. Dan alarm/buzzer tidak berbunyi karena $500 \mathrm{kPa}$ masih dalam range normal.

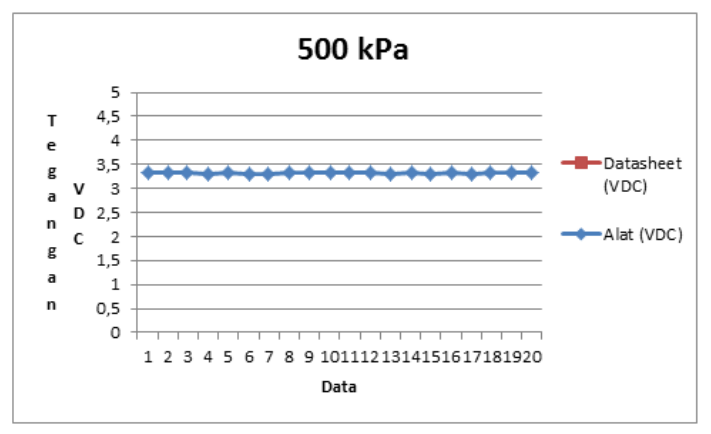

Gambar 5 Grafik Tegangan Alat Dan Datasheet

Pada Gambar 5 merupakan data hasil pengukuran pada tekanan $500 \mathrm{kPa}$ yang dilakukan sebanyak 20 kali. Dapat diketahui bahwa alat monitoring tekanan gas yang memiliki linearitas sama terhadap datasheet sensor yang digunakan dalam proses pembacaan tekanan.

\section{KESIMPULAN}

Kesimpulan dalam penelitian ini, telah dilakukan perancangan dan pembuatan alat pengukur tekanan gas medis sebagai berikut:

Alat dapat melakukan monitoring tekanan disertai bunyi alarm saat terjadi low pressure dan high pressure yang tertampil pada layar LCD.

Sensor MPX5700 dapat membaca dengan baik dari tekanan 0 - $600 \mathrm{kPa}$ yang diujikan dengan tekanan $300 \mathrm{kPa}$ didapatkan rata-rata 286,6 dengan simpangan 13,4 dan error 4,46\%, dengan tekanan $400 \mathrm{kPa}$ didapatkan rata-rata 396,75 dengan simpangan 3,25 dan error $0,81 \%$, dengan tekanan $500 \mathrm{kPa}$ didapatkan rata-rata 491,95 dengan simpangan 8,05 dan error 1,61\%, dengan tekanan $550 \mathrm{kPa}$ didapatkan rata-rata 539,75 dengan simpangan 10,25 dan error 1,86\%. Berdasarkan hasil pengujian tersebut alat tekanan gas medis dapat digunakan untuk tekanan $0-550 \mathrm{kPa}$, artinya alat dapat bekerja dengan baik.

Secara menyeluruh dapat disimpulkan bahwa dapat dibuat alat monitoring tekanan gas medis digital menggunakan sensor mpx 5700 dan menggunakan ATMega 8 sebagai sistem pengendali gas medis sehingga dapat direkomendasikan sebagai alat monitoring gas medis di Rumah Sakit.

\section{DAFTAR PUSTAKA}

[1] D. R. Wijaya, R. Sarno, and E. Zulaika, "Gas concentration analysis of resistive gas sensor array,” 2016 Int. Symp. Electron. Smart Devices, ISESD 2016, pp. 337-342, 2017.

[2] P. M. K. R. I. N. 4 T. 2016, "Penggunaan Gas Medik Dan Vakum Medik Pada Fasilitas," 2016.

[3] S. W. Su, L. Wang, B. G. Celler, and A. V Savkin, "Hammerstein Model," vol. 55, no. 5, pp. 3427-3430, 2006.

[4] D. A. N. V. Medik, "Sistem Instalasi Gas Medik," pp. 1-73, 2012.

[5] B. Latif, Zaini Wahjudi, Arif Sudarmanta, "Rancang Bangun Sistem Pengukuran Pada Alat Kalibrasi Sensor Gas Oksigen ( O 2 )," vol. 1, no. 2, 2014.

[6] P. Ramli and Elvaswer, "DETEKTOR GAS OKSIGEN DARI BAHAN SEMIKONDUKTOR TiO2 DOPING CuO," Univ. Andalas, vol. 8, no. 1, pp. 28-37, 1979.

[7] S. Madrolle, P. Grangeat, and C. Jutten, "Dual-temperature mode for quantitative analysis of gas mixtures with MOX sensor," ISOEN 2017 - ISOCS/IEEE Int. Symp. Olfaction Electron. Nose, Proc., no. 2, pp. 2-4, 2017.

[8] F. Semiconductor, "Freescale Semiconductor Integrated Silicon Pressure Sensor On-Chip Signal Conditioned , Temperature Compensated and Calibrated," 2012. 